\title{
ENTRE AS FRESTAS DA GRADE E O BARULHO DO CADEADO: A EDUCAÇÃO COMO HORIZONTE DE GARANTIA DE DIREITOS
}

\author{
Catarina de Almeida Santos ${ }^{1}$ \\ Ingrid Louize Nascimento dos Santos ${ }^{2}$
}

Resumo: O presente artigo apresenta os resultados de uma pesquisa que buscou identificar os desafios e lacunas da implementação da política socioeducativa em uma Unidade de Internação do Distrito Federal. Para realização do trabalho, utilizou-se de pesquisa bibliográfica e documental sobre o tema, além intervenções culturais com os adolescentes em cumprimento de medida socioeducativa e entrevistas semiestruturadas com especialistas. Para a análise dos dados coletados, empregou-se a perspectiva de Aguiar e Ozella (2006) com núcleos de significação. Os resultados indicam disparidades entre o que dizem os Documentos Oficiais e o que realmente acontece dentro da Unidade de Internação.

Palavras-chave: Educação; Socioeducação; Medidas socioeducativas.

\section{BETWEEN THE GAPS OF THE GRID AND THE NOISE OF THE PADLOCK: EDUCATION AS A HORIZON FOR RIGHTS GUARANTEE}

\begin{abstract}
This article presents the results of a research which has sought to identify the challenges and the gaps in the implementation of the socio-educational policy in a Juvenile Detention Center ("Unidade de Internação") of the Federal District. In order to carry out the work, we have used bibliographical and documentary research on the subject, besides cultural interventions with adolescents serving socio-educational sentences, and semi-structured interviews with specialists. In order to analyze the collected data, we have adopted Aguiar and Ozella (2006) perspective with meaning cores. The results indicate disparities between what the Official Documents say and what happens within the Juvenile Detention Center.
\end{abstract}

Keywords: Education; Socio-education; Socio-educational sentences.

\footnotetext{
${ }^{1}$ Faculdade de Educação da Universidade de Brasília. (cdealmeidasantos@gmail.com)

${ }^{2}$ Secretaria de Estado da Educação do Distrito Federal. (louize.nascimento09@gmail.com)
}

v. 21 n. 47 p. $155-173 \quad$ jul/set. 2019 


\section{INTRODUÇÃO}

Quando pivete, meu sonho era ser jogador de futebol, vai vendo Mas o sistema limita nossa vida de tal forma

Que tive que fazer minha escolha, (“Sonhar ou sobreviver" - Racionais MC's).

O Brasil é um país conhecido pelas suas dimensões continentais, mas também pelas desigualdades sociais e econômicas. $\mathrm{O}$ país que abriga, segundo o Censo IBGE 2017, cerca de 48 milhões de jovens, entre 14 e 24 anos, aparece nos dados internacionais como um dos mais violentos do mundo. A violência atinge especialmente pessoas nessa faixa etária, sobretudo nos grupos mais pobres e negros, que vivem nas periferias das grandes cidades. Nesse contexto, a demanda por políticas públicas que se efetivem para essa parcela da população se torna urgente e necessária para evitar a sua dizimação.

O homicídio de jovens entre 15 e 19 anos cresceu 23\% de 2006 a 2016, o que gerou cerca de 33 mil vítimas nessa faixa etária, segundo pesquisa da Folha de São Paulo ${ }^{3}$. Em 2016, as taxas de homicídio entre negros (42,1/100 mil ) e não negros (16/100 mil) revelam a urgência de políticas de estado para evitar o genocídio da juventude, especialmente a juventude negra e periférica que, como apontam os dados, chega a ser quase o dobro das mortes dos não negros, que são os mais atingidos pelas mortes cada vez mais precoces.

Os dados apontados anteriormente demonstram que a dizimação da juventude brasileira, especialmente a juventude negra, é o resultado fatídico da estrutura desigual da sociedade brasileira, nos seus aspectos sociais, econômicos e raciais. $\mathrm{O}$ enfrentamento dessa questão e a resolução desse problema passam pela criação de políticas públicas para evitar ou prevenir a entrada dos jovens no mundo do crime, mas também pelo combate à discriminação e pela mudança de postura de um Estado que autoriza a polícia a matar seus jovens.

Por outro lado, é preciso criar políticas e implementar ações que deem outra perspectiva de vida para aqueles que já cometeram algum ato infracional,

\footnotetext{
MENA, Fernanda. Assassinato de jovens cresce, e país tem 325 mil vítimas em 11 anos. Folha de São Paulo, São Paulo, 6 jun. 2018. Disponível em: https://www1.folha.uol.com.br/cotidiano/2018/06/assassinato-dejovens-cresce-e-pais-tem-325-mil-vitimas-em-11-anos.shtml. Acesso em: 20 outubro de 2018.
} 
como é o caso dos jovens em privação de liberdade. Nesse sentido, a Socioeducação é fundamental, pois a educação tem papel não só de garantir o desenvolvimento integral da pessoa, mas também seu preparo para conviver em sociedade e transformar a realidade, além da preparação para o mundo do trabalho.

Não só a promulgação da Constituição de 1988, mas também a aprovação da Lei no 8.069, de julho de 1990, que institui o ECA - Estatuto da Criança e do Adolescente, trazem uma série de direitos e criam uma base legal que busca a garantia da melhoria no tratamento aos adolescentes infratores, que sempre foram tidos como objeto de reparação pelo Estado.

O preconceito da sociedade em relação a esses sujeitos é um fator importante a ser considerado nesse processo de transformação social ou de permanência da realidade. Percebe-se que o adolescente, ao sair da Unidade após o cumprimento de sua medida, é inteiramente mantido à margem da sociedade, sem o estudo e sem o apoio para procurar outros meios de inserção econômica e social. A crescente onda de redução da maioridade penal reflete nitidamente a concepção que se tem do adolescente infrator perante a sociedade em geral.

Autores como Njaine e Minayo (2002) apontam o papel que a mídia desempenha na construção desse ideário, ou seja, demonstrando o poder de persuasão que os grandes veículos de comunicação têm sob a população, reforçando o discurso de ódio e discriminação a esses adolescentes e jovens.

Nesse sentido, o presente artigo é resultado de uma pesquisa do tipo qualitativa, que busca entender e/ou observar algum fenômeno sem a necessidade de obter grandes quantidades de dados, baseando-se na observação do fenômeno em sua complexidade. A pesquisa foi realizada em uma Unidade de Internação do Distrito Federal e se utilizou de observação participante no espaço em questão, ações integralizadoras com os adolescentes e de entrevistas semiestruturadas com as especialistas (pedagogas), além de análise documental. Após a construção dos dados, pôde-se criar núcleos de significações unindo as vozes de todos os sujeitos envolvidos no processo de pesquisa, contrapondo com as teorias presentes neste estudo. 


\section{ENTRE TEORIAS LIBERTÁRIAS E O SENSO COMUM PUNITIVO: A REALIDADE DO SISTEMA SOCIOEDUCATIVO}

Segundo o Estatuto da Criança e do Adolescente (1990), adolescente é o sujeito que tem idade entre 12 e 18 anos incompletos, sendo considerado pessoa em condições peculiares de desenvolvimento, e que por isso é inimputável, ou seja, não pode ser apenado. A peculiaridade do adolescente se deve ao elevado nível de vulnerabilidade social que esse indivíduo convive, principalmente em países em desenvolvimento, cuja renda está concentrada nas mãos de uma pequena parcela da população. Essa vulnerabilidade está intimamente atrelada a diversos aspectos como negligência no acesso aos direitos fundamentais, à necessidade de experimentar, à dificuldade de fazer escolhas, ao distanciamento da família e à facilidade no acesso às drogas, tudo isso atrelado à violência, que a cada dia acomete mais os jovens. Esse público ainda é alvo de grande estigmatização e inferiorização por parte da sociedade, que cobra e exerce uma grande pressão, seja para estudos ou mercado de trabalho.

De acordo com dados do Ipea - Instituto de Pesquisa Econômica Aplicada, em 2016, 49\% dos homicídios no Brasil foram sofridos por jovens de 15 a 19 anos, faixa etária englobada pela definição de adolescente na doutrina integral de direitos, trazida pelo Estatuto. Essa violência exacerbada está ligada à lógica do consumo que permeia o capitalismo, que gera na sociedade a "necessidade" de ter e estar. Essa cultura do consumo acaba por causar conflitos, amplia a exclusão social e estimula os comportamentos que suscitam embates, ampliando assim a banalização da violência e das condutas ilícitas.

O último levantamento do Sistema Nacional de Atendimento Socioeducativo - Sinase, do ano de 2016, demonstra que o público da Socioeducação é composto, na sua maioria, por homens (96\%). Esse número reflete diretamente na quantidade de unidades totalmente femininas, que se restringem a um total de 35 , enquanto o total de unidades exclusivas ao público masculino é de 419 estabelecimentos. Do total de adolescentes atendidos pela Socioeducação, grande parte se autodeclara parda ou negra (59,08\%). Já o índice de brancos é de 22,49\%, o restante divide-se em "não informado" $(16,54 \%)$, indígena $(0,98 \%)$ e amarela $(0,91 \%)$. Esse dado revela a seletividade e o racismo instituídos nos Sistemas de Segurança e no Sistema Judiciário, além disso, aponta a grande vulnerabilidade dessa parcela negra ou parda, que está mais exposta à violência e à criminalidade. Traduz, ainda, a lógica de um Estado 
que é seletivo e excludente, o racismo dos policiais e do sistema judicial e o quanto negros e pardos estão mais expostos à violência e à criminalidade.

O principal ato infracional realizado pelos adolescentes está intimamente ligado às desigualdades sociais existentes no Brasil: o roubo. Esse ato, além de revelar uma condição econômica desfavorável para esses jovens, vincula-se à ideia de que para ser é preciso ter, é preciso pertencer. A existência é condicionada não apenas ao ter comida, mas também a ter uma roupa da moda e usar um tênis "maneiro". Em segundo lugar, vem o crime análogo ao tráfico de drogas, que, se tratando de Brasil, é nítida a facilidade encontrada para que esses jovens adentrem no crime e no uso de entorpecentes. A questão é tão grave que se levarmos em conta o papel desempenhado por esses jovens na cadeia hierárquica do tráfico, em sua maioria são "aviãozinho" , o que, segundo algumas pesquisas recentes (GALDEANO; ALMEIDA, 2018), pode ser considerado trabalho infantil. O envolvimento com o tráfico, especialmente da população pobre e negra, está ligado diretamente à condição do roubo, ou seja, não é uma simples escolha, mas uma condição exposta a essa parcela da sociedade que necessita sobreviver.

Esses jovens, convivendo em um meio violento e de poucas oportunidades, se veem diante de uma realidade pouco promissora e acabam por reproduzir todas essas ações violentas, culminando em atos ilícitos. E, ao serem deflagrados, são enviados ao sistema judiciário que, à luz do ECA (1990), os encaminha para os órgãos responsáveis pelo cumprimento de acordo com a medida socioeducativa sancionada, conforme as medidas elencadas no artigo 112 do Estatuto. De acordo com o ECA, caso seja verificada a prática de ato infracional, podem ser aplicadas as seguintes medidas: advertência; obrigação de reparar o dano; prestação de serviços à comunidade; liberdade assistida; inserção em regime de semiliberdade; internação em estabelecimento educacional; e qualquer uma das medidas previstas no art. 101, dos I a VI (BRASIL, 1990).

${ }^{4}$ Aviãozinho: indivíduo que repassa drogas, pratica a venda de drogas, ou apenas transporta para alguém. (dicionário dos socioeducandos). 


\section{"BANDIDO BOM É BANDIDO MORTO"}

As medidas estabelecidas pelo ECA, no entanto, são vistas pela sociedade como injustas, levando-se em consideração que grande parte da população entende que, ao passo que esses jovens não sofrem sanções mais duras, as penas aplicadas são provas da impunidade. No senso comum, os espaços de cumprimentos das medidas socioeducativas não passam de colônias de férias, onde os adolescentes dormem, comem e não trabalham e ainda são sustentados por todos os trabalhadores, com o pagamento dos impostos abusivos ao Estado. Com isso, Volpi et al. (2008, p. 158) mostram a importância de diferenciar inimputabilidade e impunidade, pois "a inimputabilidade - causa de exclusão da responsabilidade penal - não significa, absolutamente, irresponsabilidade pessoal ou social”.

A inimputabilidade é somente a circunstância de o adolescente não responder penalmente devido a sua fase de desenvolvimento, que necessita de um atendimento diferente do ofertado aos adultos, mas que de forma alguma não será responsabilizado pelo ato infracional cometido.

Essa sensação de impunidade e o engano ou falta de conhecimento têm sido os grandes obstáculos no que diz respeito à implementação do ECA na realidade brasileira, somados ainda à crescente onda de violência e aos clamores populares pela redução da maioridade penal no país. Nesse sentido, a Socioeducação encontra-se dividida entre trabalhar com o adolescente em sua totalidade, entendendo sua condição peculiar, e responder à sociedade que reclama por meios mais penosos e amargos no tratamento com esses sujeitos.

A demanda pela punição física e pelo castigo-espetáculo é crescente na população. A cada dia, a sociedade clama por métodos mais incisivos, a prisão do corpo aparenta não ser mais suficiente para saciar a fome de justiça que vive nas vítimas e nos seus familiares. O suplício ${ }^{3}$ encontra-se na relação entre "o tipo de ferimento físico, a qualidade a intensidade, o tempo dos sofrimentos com a gravidade do crime, a pessoa do criminoso, o nível social de suas vítimas" (FOUCAULT, 1987, p. 31).

\footnotetext{
Suplício: pena corporal, dolorosa, mais ou menos atroz [dizia Jaucourt]; e acrescentava "é um fenômeno inexplicável a extensão da imaginação dos homens para a barbárie e crueldade" (enciclopédia verbete suplício).
} 
Nesse sentido, o tipo de punição está intimamente ligado a diversos fatores, não só ao ato infracional, mas ao nível social das vítimas e ao nível social do agressor. Quando se trata de tratamento diferenciado, impossível não recordar o episódio do índio Galdino ${ }^{6}$, acontecido na capital federal, que corrobora com a ideia de que a lei só funciona para alguns e que o Sistema Judiciário é seletivo. Os privilégios foram levados ao tribunal. É como aquele velho ditado popular: "a corda sempre arrebenta do lado mais fraco" e, completamos, "do lado mais pobre". Ser filho de ministro do TSE e estar em uma boa condição social fazem com que qualquer ato infracional, por mais grave que seja, tenha seu desfecho manipulado e abrandado por amigos e favores, o famoso "jeitinho brasileiro". Apesar de não ser o foco central deste trabalho, é importante ressaltar que

É salutar ponderar que não são apenas os adolescentes pobres,
negros, moradores de aglomerados que cometem atos
infracionais, entretanto, por razões que não são foco direto deste
trabalho, a maioria absoluta dos adolescentes que estão
cumprindo algum tipo de medida socioeducativa apresentam este
perfil (ALVES, 2010, p. 29).

Similar ao que acontecia em 1670, a ostentação dos suplícios, onde pessoas tidas como transgressoras da lei e da moral vigente eram queimadas e esquartejadas em praça pública como forma de impor medo e perpetuar a autoridade do Rei sob seus súditos, o clamor popular vigente nesta sociedade se assemelha ao suplícios vividos há mais de 300 anos, e não se dá apenas por apelo popular, mas também pelos discursos de poder, nos quais o que importa são "os mecanismos que controlam, seguem, punem e reformam o delinquente" (FOUCAULT, 1987 p. 186). Com o intuito apenas de punir e privar de liberdade, o sistema prisional está em pleno colapso, são celas cada vez mais lotadas e sem perspectivas de uma vida em liberdade plena, com exercício da cidadania e com inserção profissional. A socioeducação acaba por seguir os mesmos passos e comumente suas unidades são chamadas de "escola do crime”, onde adolescentes permanecem até saírem ou completarem vinte e um anos (liberação compulsória), sendo agora sujeitos adultos e, portanto, passíveis de pena criminal e expostos ao sistema prisional.

Outro fato que colabora com a pressão sobre o Sistema Socioeducativo é a grande reincidência dos jovens, que muitas vezes saem do sistema e acabam

\footnotetext{
${ }^{6} \mathrm{Na}$ madrugada de 20 de abril de 1997, cinco jovens de classe média atearam fogo no cacique do povo pataxó-hã-hã-hãe, que dormia no banco da parada de ônibus da 704 Sul. Galdino teve $95 \%$ do corpo queimado e morreu no dia seguinte ao ataque (ALVES, 2017).
} 
retornando para a criminalidade, sendo obrigados a cumprirem medidas socioeducativas, ou, se forem maiores de dezoito anos, acabam por ingressar no sistema prisional de fato. Existem alguns dados quantitativos sobre essa reincidência, mas não são conclusivos devido à falta de pesquisas que versam sobre a temática. No entanto, vale destacar os dados disponíveis, apesar dos limites que eles apresentam. Segundo a Pesquisa "E aí eu voltei para o corre Estudo da Reincidência Infracional do Adolescente no estado de São Paulo" (INSTITUTO SOU DA PAZ, 2018), realizada em São Paulo na Fundação Casa, $66 \%$ dos adolescentes que cumpriram medida socioeducativa retornam para o Sistema cometendo novamente ato infracional.

\section{SOCIO+EDUCAÇÃO = POLÍTICA PÚBLICA}

No sentido de conceber a socioeducação como uma junção do social com a educação e não apenas como uma política de correção social, se faz necessário debater a concepção da Socioeducação e mostrar que esta não é e não pode ser meramente uma falácia jurídica e sim um Sistema que englobe as mais variadas políticas públicas. Visando, ainda, construir novos conceitos de vida para esse adolescente, pautados nos princípios éticos da vida social, com seus direitos garantidos e com a oportunidade de manter-se cidadão sem o acometimento de novas condutas ilícitas (VOLPI et al., 2008). É imprescindível que se pense a Socioeducação como política pública de fato, e que ela interaja com todos os setores da sociedade civil, favorecendo uma formação de qualidade e meios reais para que o adolescente saia do sistema com plenas condições de viver em liberdade. Para tanto, a Educação se torna a ferramenta principal para essa transformação social, uma educação pautada na liberdade, na cidadania plena e no exercício de todos esses ensinamentos e vivências, lá fora, lá na rua, "na quebrada”.

Pensar a Socioeducação como política pública é garantir a esses sujeitos direitos que eles não tiveram antes de entrar no Sistema Socioeducativo. Como afirma Sales (2007), há sempre uma suposição de que todo adolescente pobre é um "menor infrator". Isso se deve ao fato de que, em toda a linha do tempo histórica, no que diz respeito a crianças e adolescentes, principalmente de classes populares, terem sido tratados de forma marginalizada, criando-se internatos para que estes fossem "ressocializados", mas como ressocializar alguém em uma sociedade que o expulsa e nega direitos fundamentais? 
Cordeiro e Volpi (2010) afirmam que os mais afetados pelo desemprego e marginalização do sistema educacional são os mais propensos a sofrerem violência por parte da arbitrariedade da polícia e dos agentes de repressão do Estado. Ou seja, o sistema socioeducativo é preparado, assim como o código de Mello de 1979, para os sujeitos marginalizados da sociedade. No Brasil, você não vê um filho de magistrado cumprindo medida socioeducativa, como também não se vê cumprindo pena no sistema prisional.

A relação dos socioeducandos com a escola se deu/dá prioritariamente pela matrícula obrigatória, sem que exista uma frequência ativa com participação efetiva no espaço escolar. Paralelamente a essa escolarização obrigatória, o jovem evade e vai aprender na rua, na labuta, na sobrevivência diária. Oliveira (2003) ressalta que vindos de inúmeras experiências educacionais, onde muitos apresentam defasagens e mudanças contínuas, a escola se mostra pouco contributiva para a realidade de cada um deles. Freire e Shor (1986), no livro Medo e ousadia, mostram o cotidiano do professor e afirmam que o Sistema Escolar convenceu muitos desses estudantes de que a própria escola não os levava a sério e que, por isso, a seriedade por parte dos alunos é inexistente.

Os jovens em cumprimento de medida socioeducativa, em sua maioria, vêm de diversas reprovações e com isso acabam desacreditados e sem a valorização da sua própria cultura. Esses jovens acabam por se evadirem da escola, deixando tempo mais livre para o acometimento de atos infracionais e/ou o uso de entorpecentes, favorecendo, com isso, a arbitrariedade policial, que tem nesse perfil de jovem a legitimação da violência e do aprisionamento de corpos descartáveis, como aponta Leal (2014), no artigo "A mulher e o sistema penal: de vítima à infratora e a manutenção da condição de Subalternidade".

Esses jovens, após passarem pela Socioeducação, seja medida de internação ou em meio aberto, acabam marcados, estigmatizados, como se perdessem todos os créditos perante a sociedade e perante seus professores, o que dificulta ainda mais o retorno à sociedade sem o acometimento de novas condutas transgressoras (OLIVEIRA, 2003; SOUZA, 2008).

Durante a realização da pesquisa, pôde-se perceber que algumas falas das pedagogas, juntamente com a observação participante, iam de encontro ao relato dos adolescentes ouvidos no processo de pesquisa e, para que não se tornasse repetitivo, optou-se por reunir núcleos de significação pautados nas ideias de Aguiar e Ozella (2006). 


\title{
NÚCLEO 1: “A SOCIOEDUCAÇÃO COMO PROCESSO DE (RES)SOCIALIZAÇÃO”
}

Conhecer as concepções de quem está lidando diariamente com os adolescentes e desempenha um papel determinante no processo socioeducativo é, além de importante, crucial para entender todas as ações empreendidas na Unidade, a fim de que se alcance o principal sujeito da Socioeducação, que é o adolescente, e o principal objetivo, que é a sua formação.

Esse núcleo trabalha principalmente com o olhar do pedagogo, visto que as duas entrevistadas são pedagogas, sobre a Socioeducação, entendendo que é um campo relativamente novo e com pesquisas recentes acerca da significação da socioeducação, além do conceito adjetival que foi empregado na promulgação do ECA. Para a Entrevistada 1, a

\begin{abstract}
Socioeducação é um fazer social e educativo, que tem por objetivo inserir/ reinserir o indivíduo ao meio social. E aí quando eu digo meio social, entra as suas relações interpessoais, a sua relação indivíduo - instituições, indivíduo - estado, indivíduo regras sociais, está tudo dentro desse pacote e a Socioeducação ela vem agindo nisso daí, em auxiliar o indivíduo a conviver socialmente, construir uma vida social responsável (Entrevistada $1)$.
\end{abstract}

A Entrevistada 2 compactua da mesma visão acerca do conceito de Socioeducação, como é demostrado na sua fala: "Processo socioeducativo seria a inserção social a partir da realidade do adolescente e de suas dificuldades mediante um ato infracional praticado". O que é comum na fala das entrevistadas, bem como na observação participante, é o olhar da REssocialização, REinserção no que diz respeito a todo o processo socioeducativo, que visa particularmente "sanar" as anomalias existentes nos socioeducandos, padronizando seus comportamentos em condutas lícitas para que assim seus corpos não fiquem aprisionados. Essa utilização do prefixo "re" coaduna-se na fala das autoras Cella e Camargo (2009). O uso reiterado dessas falas acaba gerando um reforço à ideia amplamente difundida na história da Socioeducação e no tratamento dos menores através dos reformatórios e/ou internatos. É a reafirmação de que o indivíduo da Socioeducação transgrediu 
regras sociais somente por fatores pessoais, sem que haja uma reflexão acerca de todos os envolvidos: o Estado, a família, a Escola.

O Sistema Socioeducativo não é apenas um reformatório social de jovens transgressores: "a socioeducação é entendida como várias formas de aprendizado que envolvam a sociedade e o indivíduo" (Entrevistada 2). Nessa perspectiva, é preciso que a Socioeducação seja esse espaço educativo e cultural, que busca a integração desse jovem com o meio social e com as regras sociais impostas, mas é primordial que valorize as especificidades desse jovem, que dê voz às angustias vividas, ofereça um acompanhamento psicológico e que ampare a família, para que, ao retornar após o cumprimento da medida socioeducativa, ele consiga permanecer em seu leito familiar e gozar de seus direitos, não esquecendo dos deveres, das obrigações.

A Educação, apesar dos grandes golpes que vem sofrendo, como corte de verbas e redução significativa nos orçamentos, permanece sendo a principal ferramenta de transformação social, seja pelo campo da escolarização ou pela oportunidade de empoderamento cidadão.

Eu acho que o papel da educação na Unidade de internação ele é basilar, se você me perguntar qual é a parte mais importante da unidade é a escola. A escola é o espaço que deve ser maior valorizado, receber maior atenção em todos os sentidos de infraestrutura, mas também de pessoal e de cuidado de formação e tudo mais (Entrevistada 1).

A percepção do papel da educação no campo socioeducativo vem sendo basilar, e é a ferramenta com a qual os profissionais poderão de alguma forma trabalhar, apesar da precariedade. Mas o mais importante é pensar que educação é essa que está sendo ofertada, pois, em sua maioria, os socioeducandos vêm de diversas rupturas e defasagens, ligadas a fatores cognitivos, sociais, financeiros e culturais, como bem aponta Oliveira (2003).

A educação deve ir além da escolarização formal, é necessária uma desconstrução do bê-á-bá, se faz necessária uma significação desse conhecimento, um empoderamento desses estudantes para que a educação não fique "presa" às linhas do caderno, mas que crie asas e vá ao encontro do jovem no mundo lá fora, lá na rua... onde irá colocar em prática todos os ensinamentos. Esses jovens serão os atores transformadores de sua própria realidade, serão a ação da educação em si. 


\begin{abstract}
Nosso papel não é falar ao povo sobre nossa visão de mundo, ou tentar impô-la a ele, mas dialogar com ele sobre a sua e a nossa. Temos de estar convencidos de que a sua visão do mundo, que se manifesta nas várias formas de sua ação, reflete a sua situação no mundo, em que se constitui. A ação educativa e política não pode prescindir do conhecimento crítico dessa situação, sob pena de se fazer "bancária" ou de pregar no deserto (FREIRE, 2005, p. 100).
\end{abstract}

Daí surge a necessidade da representação social e do reconhecimento do adolescente pelo profissional que está lidando com ele todos os dias, pois, além da teoria e das imposições legais, esse profissional representativo irá entender os anseios, os medos e principalmente as feridas vividas também em sua pele.

\title{
NÚCLEO 2: "EDUCAÇÃO PARA LIBERDADE”
}

Parece metafórico falar de educação para a liberdade em uma unidade de internação. Pode aparentar à primeira vista a questão da liberdade de somente não estar aprisionado, de estar livre em seu significado mais simples. Porém, utilizando conceitos de Paulo Freire de educação libertária, teremos significações para além das grades e dos cadeados, e é o que será abordado nesse núcleo.

\begin{abstract}
A educação para a liberdade liberta de paradigmas, ela promove essa liberdade do sujeito, preparando o adolescente para viver livre, e para ele entender a sua própria liberdade e construir a sua liberdade, é como a gente tem uma pedagogia do oprimido (Entrevistada 1).
\end{abstract}

Pensar a educação para a liberdade implica pensar além dos muros da Unidade, é ofertar oportunidades que sempre foram negadas a esses jovens, é entender seus ciclos violentos e não apenas julgar o seu ato infracional, é saber que a sua família poderia depender do seu ato ilícito para sobreviver. Para tanto, é indispensável que a educação englobe todos esses aspectos, favorecendo um ensino real, e que possibilite uma saída dos caminhos ilícitos, e a profissionalização seria esse novo caminhar do adolescente. 
Logo, para enfrentar essa onda normalizadora e protagonizar o jovem a partir da sua cultura e da realidade vivida, é imprescindível valorizar outras linguagens e possibilitar poder ao jovem através de outras ferramentas como o RAP, as rimas e a utilização desse espaço de fala para problematizar e enfrentar a realidade.

"Aqui é assim, na periferia,

Moleque bem novo fazendo sua correria.

Aqui é assim, na periferia,

Moleque bem novo fazendo sua correria.

Pra tirar da miséria a sua família"

O RAP vem sendo a linguagem que mais alcança os jovens em cumprimento de medida, viabilizando um acesso a espaços antes negligenciados. A Unidade pesquisada recebeu um grande prêmio no final do ano passado pelo trabalho com os adolescentes. Através da música, da rima e da poesia, os jovens adquirem o poder de fala e, através desse poder, garantem alternativas à criminalidade que os cerca, dentro e fora da Unidade.

E nos espaços educativos que eu já experienciei essa é uma prática tentada muitas vezes, não é bem-sucedida por conta de dificuldades de trabalho mesmo. Mas essa educação para liberdade ela é desenvolvida nos espaços educativos assim, com exemplo da nossa unidade, a gente faz roda de conversa, faz cine debate, atividades formativas, palestras e tudo mais, até o RAP mesmo que a gente trabalha, tudo é muito voltado para o para essa construção dessa liberdade (Entrevistada 1).

Com a inserção participativa na pesquisa, ficou nítida a preocupação da gerência em oportunizar espaços de diálogo, de construção de arte e cultura. Apesar das dificuldades enfrentadas, como falta de verba e de agentes socioeducativos suficientes para garantir a segurança dos adolescentes, os festivais e festas comemorativas acontecem. E esses momentos são carregados de expectativas pelos adolescentes, se tornando uma oportunidade de sair do quarto e pelo menos por alguns minutos relembrar a liberdade de ser um

\footnotetext{
${ }^{7}$ Trecho retirado da dissertação "Oficinas Rap para adolescentes: proposta metodológica de intervenção psicossocial em contexto de provação de liberdade”, de Tomasello (2006).
} 
jovem, de curtir suas músicas e olhar para outros pares, que também por motivos semelhantes estão agora sob os mesmos muros altos e cinzentos.

\title{
NÚCLEO 3: "E QUE OS AGENTES DESSE TRABALHO SOCIOEDUCATIVO CONSIGAM ENCONTRAR UMA FALA COMUM OU UMA PRÁXIS...”
}

Sentimentos, opiniões, concepções religiosas, direções ideológicas e formações diversificadas. Essas características, entre outras, são os ingredientes do caldeirão humano de cada ser, são regidos por seus sentidos e experiências pessoais, o que gera um reflexo direto no seu papel desempenhado, seja numa Unidade de internação ou numa escola regular. Cada profissional tem suas preferências, e isso, de alguma forma, o modifica e transforma em sua forma de agir.

\begin{abstract}
Eu acho que é um grande desafio da Socioeducação dentro do sistema socioeducativo e mais especificamente dentro das unidades de internação é conseguir fazer com que o trabalho socioeducativo seja mais articulado, seja mais interdisciplinar. E que os agentes socioeducativos consigam encontrar uma fala comum ou uma práxis um pouco mais consensuada. Me refiro a essa dificuldade de trabalhar junto entre o especialista na área, que é na área de serviço social, psicologia e pedagogia e os agentes socioeducativos que atuam mais na área disciplinar, de segurança (Especialista 1).
\end{abstract}

A fala das profissionais corrobora com a realidade observada durante a pesquisa de campo e nas conversas com os socioeducandos. Eles citam a dificuldade de ter um trabalho conjunto, em que todos os setores da Unidade andem lado a lado, respeitando a fala de cada um e principalmente os direitos ali postos pelo Sinase, pelo Estatuto da Criança e do Adolescente e por todas as diretrizes que versam sobre a Socioeducação e que orientam o trabalho diferenciado que deve ocorrer atrás daqueles altos muros cinzentos. É necessário ter uma práxis socioeducativa em que todos possam trabalhar em conjunto de forma satisfatória.

As diferentes formações e a falta de exigência no concurso de pessoas que já trabalharam ou se especializaram na área refletem no dia a dia dentro da 
unidade, e claro, respingam no processo socioeducativo e nos adolescentes que ali cumprem suas medidas sancionadas.

Eu li a história da Malala. Ela teve que fugir do Afeganistão para falar e a ONU escutar. Podem existir leis lá fora, mas a partir do momento que a gente está aqui dentro é sob as leis e regras deles: os agentes de segurança. Ninguém vai estar do nosso lado 24 horas para fiscalizar e impedir alguma coisa de acontecer, quem decide aqui são os agentes. Eles falam e a gente é obrigado a obedecer e ninguém vai poder mudar isso, nem hoje e nem amanhã, pois quem abre a porta do quarto e faz a escolta para onde a gente for, todos os dias, são os agentes (DINIZ; TALIA, 2018, p. 63).

O percurso entre o que afirmam os documentos oficiais e o que realmente acontece dentro da Unidade é um caminho longo demais e que por muitas vezes é negligenciado. Os agentes de segurança se legitimam através do descrédito e do clamor punitivo que assombra a Socioeducação. Apesar de não ser o foco específico deste trabalho, é importante tratar dessa questão silenciada. Os adolescentes em cumprimento de medida socioeducativa têm direitos assim como outros jovens de sua faixa etária e, devido a sua condição peculiar de desenvolvimento, devem ser resguardados pelo Estado, pela Família e pela Sociedade. Porém, esses jovens são invisibilizados durante sua vida inteira e somente passam a ser vistos quando cometem atos infracionais, ao se transformarem em "menores infratores", e essa visão negativa gera preconceitos no tratamento oferecido, seja na Escola ou no retorno ao convívio social, ou na própria Unidade.

Aliado a tudo isso, ainda existe a escassez de investimentos na área da Socioeducação, justamente pelo descrédito e pelo desprestigio da área social, tida como escolarização do crime.

\section{CONSIDERAÇÕES FINAIS}


A Socioeducação, apesar de ter a educação como sua base, ainda é pouco difundida nos meios acadêmicos e nas Faculdades de Educação. Esse tema bastante pertinente se faz ainda mais necessário após essa onda midiática que envolve esses jovens, o encarceramento de massas e o aumento a cada dia do genocídio da população preta e pobre.

Entender o processo socioeducativo em sua implementação é trazer indagações acerca da sua praticidade e do seu papel social. Contudo, sem esquecer das dificuldades e dos desafios encarados a cada dia. Para tanto, esta pesquisa buscou mostrar a realidade e a disparidade existente entre a legislação propriamente dita e outorgada e o que realmente acontece por trás daqueles grandes muros e das imensas fileiras aos sábados (dia de visita familiar).

Servindo como escape e palanque para desmistificar rótulos arcaicos sob esses jovens, este trabalho contribuiu para tornar a academia, com seus autores renomados e inalcançáveis, um lugar de reflexão e acesso, um espaço de diálogo com a realidade, para que o que seja falado dentro de sala de aula chegue lá na perifa e envolva esses adolescentes, protagonizando suas histórias e dando voz aos seus gritos de dor e sofrimento. E que num futuro bem próximo, estejamos estudando somente a história da Socioeducação e suas contribuições para o novo educar, a nova educação social, sem que seja redundância, mas sim uma reafirmação do real papel educativo, do poder da Educação na garantia de direitos e na possibilidade de viver e não apenas sobreviver!

\section{REFERENCIAS}

AGUIAR, Wanda Maria J.; OZELLA, Sergio. Núcleos de significação como instrumento para a apreensão da constituição dos sentidos. Psicologia: Ciência e Profissão, Brasília, v. 26, n. 2, jun. 2006.

ALVES, Vanessa. A Escola e o Adolescente sob medida sócio-educativa em Meio Aberto. Rev. Bras. Adolescência e Conflitualidade, n. 3, p. 23-35, 2010.

ALVES, Pedro. Vinte anos após o crime, assassinos de Galdino reconstroem a vida. Metrópoles, Brasília, 20 abr. 2017. Disponível em: https://www.metropoles.com/distrito-federal/justica-distritofederal/vinte-anos-apos-o-crime-assassinos-de-galdino-reconstroem-avida. Acesso em: 04/11/2018. 
BRASIL. Estatuto da Criança e Adolescente. Lei n 8.069, de 13 de julho de 1990. Dispõe sobre o Estatuto da Criança e do Adolescente e dá outras providências. Brasília, DF: Casa Civil, [1990]. Disponível em: http://www.planalto.gov.br/ccivil 03/leis/18069.htm. Acesso em: 09/08/2018.

BRASIL. Presidência da República. Secretaria Especial dos Direitos Humanos. Conselho Nacional dos Direitos da Criança e do Adolescente. Sistema Nacional De Atendimento Socioeducativo - SINASE/Secretaria Especial dos Direitos Humanos. Brasília: CONANDA, 2006.

BRASIL. Sistema Nacional de Atendimento Socioeducativo (Sinase). Lei ${ }^{\circ}$ 12.594, de 18 de janeiro de 2012. Institui o Sistema Nacional de Atendimento Socioeducativo (Sinase), regulamenta a execução das medidas socioeducativas destinadas a adolescente que pratique ato infracional [...]. Brasília, DF: Casa Civil, [2012]. Disponível em: http://www.planalto.gov.br/ccivil 03/ ato20112014/2012/lei/112594.htm. Acesso em: 26/07/201

CELLA, Silvana Machado; CAMARGO, Dulce Maria Pompêo de. Trabalho Pedagógico com adolescentes em conflito com a lei: feições da exclusão/inclusão. Educ. Soc., Campinas, v. 30, n. 106, p. 281-299, jan./abr. 2009 .

CORDEIRO, Consuelo. Martins. César; VOLPI, Mario. Pesquisa quantitativa sobre adolescentes privados de liberdade no Brasil. In: VOLPI, Mario. O adolescente e o ato infracional. 8. ed. São Paulo: Cortez, 2010.

DINIZ, Debóra; TALIA. Cartas de uma menina presa. Brasília: Letraslivres, 2018.

DUARTE, Newton. Relações entre conhecimento escolar e liberdade. Cadernos de Pesquisa [online], v. 46, n. 159, p. 78-102, 2016.

FOUCAULT, Michel. Microfísica do poder. Rio de Janeiro: Edições Graal, 1979.

FOUCAULT, Michel. Vigiar e punir. Petrópolis: Vozes, 1987.

FREIRE, Paulo. Pedagogia do Oprimido. 47. ed. Rio de Janeiro: Paz e Terra, 2005. 
FREIRE, Paulo; SHOR, Ira. Medo e ousadia: o cotidiano do professor. 12. ed. Rio de Janeiro: Paz e Terra, 1986.

GALDEANO, Ana Paula; ALMEIDA, Ronaldo (Coord.). Tráfico de drogas entre as piores formas de trabalho infantil: mercados, famílias e rede de proteção social. São Paulo: CEBRAP, 2018. Disponível em: https://cebrap.org.br/wp-content/uploads/2018/11/Tr\%C3\%A1fico-deDrogas-Trabalho-Infantil_ebook.pdf. Acesso em: 05/12/2018

INSTITUTO SOU DA PAZ. Aí eu voltei para o corre: estudo da reincidência infracional do adolescente no estado de São Paulo. São Paulo: Instituto Sou da Paz; CONDECA: Secretaria de Desenvolvimento Social do Estado de São Paulo, 2018. 58 p.

LEAL, Jackson da Silva. A Mulher e o Sistema Penal: de vítima à infratora e a manutenção da condição de subalternidade. Revista de Estudos Jurídicos Unesp (online), v. 18, n. 27, 2014. Disponível em:

https://ojs.franca.unesp.br/index.php/estudosjuridicosunesp/article/view/ 1295/1343. Acesso em: 14/06/2018.

MENA, Fernanda. Assassinato de jovens cresce, e país tem 325 mil vítimas em 11 anos. Folha de São Paulo, São Paulo, 6 jun. 2018. Disponível em: https://wwwl folha.uol.com.br/cotidiano/2018/06/assassinato-de-jovens-cresce-epais-tem-325-mil-vitimas-em-11-anos.shtml. Acesso em: 15/08/2018.

NJAINE, Kathie; MINAYO, Maria Cecília de Souza. Análise do discurso da imprensa sobre rebeliões de jovens infratores em regime de privação de liberdade. Revista Ciência \& Saúde Coletiva, Rio de Janeiro, n. 7, v. 2, p. 285297, 2002.

OLIVEIRA, Maria Cláudia Santos Lopes de. Inserção escolar no contexto das medidas socioeducativas: "sem escola a gente não é nada". In: SUDBRACK, Maria Fátima Olivier et al. (Org.). Adolescentes e drogas no contexto da Justiça. Brasília: Plano, 2003.

PEREIRA, Éder Fabrício; PEREIRA, Talita C. Fidélis. Ressocialização: educação no sistema carcerário, [S.I.: s.n.], 2008. Disponível em: http://www.fap.com.br/fapciencia/002/edicao_2008/009.pdf. Acesso em: 8 jun. 2018. 
SALES, M. A. Invisibilidade Perversa: Adolescentes infratores como metáfora da violência. SP: Cortez, 2007.

SOUZA, Tatiana Yokoy de. Um estudo dialógico sobre institucionalização e subjetivação de adolescentes em uma casa de semiliberdade. São Paulo: IBCCRIM, 2008.

TOMASELLO, Fábio. Oficinas Rap para adolescentes: proposta metodológica de intervenção psicossocial em contexto de provação de liberdade. Dissertação (mestrado em Psicologia) - Instituto de Psicologia da Universidade de Brasília, Universidade de Brasília, Brasília, 2006.

TOMASELLO, Fábio; CONCEIÇÃO, Maria Inês Gandolfo; PEREIRA, Sandra Eni F. N. Oficina R. A. P. In: SUDBRACK, Maria Fátima Olivier et al. (Org.). Adolescentes e drogas no contexto da Justiça. Brasília: Plano, 2003.

VOLPI, Mário; SARAIVA, João Batista; KOERNER JÚNIOR, Rolf. Adolescentes privados de liberdade: a normativa nacional e internacional \& reflexões acerca da responsabilidade penal/FONACRIAD. 4. ed. São Paulo: Cortez, 2008. 